\title{
Importancia de los mapas conceptuales para la organización y representación de los contenidos en las Ciencias de la Información
}

\author{
Suleidy Contreras Rodriguez \\ Facultad de Comunicación de la Universidad de la Habana - Cuba
}

ANÁLISIS / ANALYSIS

\begin{abstract}
Resumen
Se realiza una descripción de los mapas conceptuales a partir de sus definiciones, componentes, características, tipología, principios y usos para sus aplicaciones. Se caracteriza el proceso de organización y representación de los contenidos, como un proceso macro que incluye varios subprocesos de gran importancia para el desempeño de los profesionales de la información. Se valora la influencia de la aplicación de mapas conceptuales para la organización y representación de los contenidos en las Ciencias de la Información, destacando su impacto con las nuevas tecnologías de información y las comunicaciones.
\end{abstract}

Palabras clave

Mapas conceptuales ; Ciencias de la Información ; Organización de contenidos

Importance of concept maps for the organization and representation contained in the Information Sciences

Abstract

A description of the concept maps from their definitions, components, characteristics, types, principles and uses for their applications. It characterizes the process of organization and presentation of the contents as a macro process that includes multiple threads of great importance for the performance of information professional. Evaluate the influence of the application of concept maps for the organization and representation contained in the Information Sciences, highlighting the impact of new information technologies and communications.

Keywords

Concept maps ; Information Science ; Information organization

\section{Introducción}

La bibliotecología es una disciplina que surge en el siglo XIX como antecedente de la Ciencia de la información. Después de grandes transformaciones paradigmáticas en su campo de aplicación se señala el 1962 como el año de constitución formal de la disciplina Ciencia de la Información en Estados Unidos, aunque el primer uso oficial del vocablo ocurrió en 1958, al fundarse el Institute of Información Scientists (IIS) en Gran Bretaña (Linares,2005, p.1).

Desde entonces, la organización y representación de contenidos ha adquirido un nuevo enfoque para las organizaciones de información. Los mapas conceptuales son una poderosa herramienta muy desarrollada en la disciplina Ciencias de la información, pues poseen un alto grado de visualización donde se concentra gran cantidad de información en un mismo plano. Los mapas conceptuales son una técnica que cada día se utilizan más en los 
diferentes niveles educativos ya que les permite a los alumnos construir los conocimientos previos de manera que estos puedan organizar, interrelacionar y fijar el conocimiento.

Por las características que poseen los mapas conceptuales las organizaciones de información han hecho uso de los mismos, para crear productos informativos estructurados con un alto valor agregado. La tendencia es crear sistemas cada vez más parecidos a nuestros modelos mentales y comprender una mayor cantidad de conocimientos.

La gran cantidad de publicaciones del tema que se visualizan en la web están orientadas hacia la aplicación de los mapas conceptuales en las Ciencias Sociales, Ciencias de la Salud, Ciencias Biológicas, Ciencias Naturales y de mayor magnitud en la Educación por su origen y contribución en el proceso educativo. Lo más representativo de la literatura sobre la materia, es que no existe una carencia de investigaciones que realicen análisis minucioso de la utilidad de los mapas conceptuales para la organización y representación de la información en la Ciencias de la Información. Para demostrar la importancia de lo anteriormente expuesto se plantea el siguiente sistema de objetivos:

Objetivo general: Demostrar la importancia y aplicación de los mapas conceptuales para la organización y representación de los contenidos en las Ciencias de la información.

\section{Objetivos específicos}

- Caracterizar los mapas conceptuales.

- Caracterizar el proceso de organización y representación de contenidos en la disciplina Ciencias de la Información.

- Valorar la influencia de la aplicación de los mapas conceptuales en la organización y representación de los contenidos para las Ciencias de la Información.

Novedad de la investigación: Se pretende realizar un estudio descriptivo de los mapas conceptuales en la disciplina Ciencias de la información.

Alcance de la investigación: Se pretende analizar la aplicación de los mapas conceptuales desde la perspectiva práctica para la organización y representación de los contenidos en las Ciencias de la Información.

Tipo de investigación: Cualitativa (descriptiva).

\section{Métodos y procedimientos}

Para la presente Investigación se utilizaron diferentes métodos que sirvieron de apoyo para el análisis bibliográfico. Se consultaron fuentes primarias y secundarias a partir del análisis documental clásico. En este sentido se realizó una revisión de la bibliografía consultada con no menos de diez años de retrospección, en la cual se consultaron libros, revistas, manuscritos. Se observó a través de la revisión de la bibliografía la presencia de gran cantidad de documentos en formato digital, ya que es un tema novedoso que despierta el interés de muchos autores. El estilo en que se describe la bibliografía del documento es el APA. Los métodos utilizados para el desarrollo de la investigación son:

Método Lógico Histórico: Con el fin de analizar los principales postulados del tema.

Método Sistémico: Aplicado para establecer los principales componentes de la Investigación y la relación que hay entre ellos.

De gran utilidad fue la consulta de artículos que hacen referencias a la publicación "Aprendiendo a aprender" publicado en 1988 como primer libro realizado por el estadounidense Joseph Novak creador de los mapas conceptuales. Es un libro clásico del tema en la literatura que describe la importancia de la elaboración de los mapas conceptuales para lograr un aprendizaje significativo.

Resulta muy interesante el artículo "Psicología Educativa: Un punto de vista Cognoscitivo" realizado por otros de los grandes autores que han a portado al tema de los mapas conceptuales, David Ausubel, mexicano. En el artículo se 
Importancia de los mapas conceptuales para la organización ...

exponen los elementos fundamentales de la Teoría de Ausubel que inciden en la creación de los mapas conceptuales.

\section{Estructura de la investigación}

Capítulo 1. Los Mapas conceptuales

Capítulo 2. La Organización y representación de los contenidos (ORC) en las Ciencias de la Información.

Capítulo 3. Influencia de la aplicación de los mapas conceptuales en la ORC en las Ciencias de la Información.

\section{Capítulo 1 - Los mapas conceptuales}

\section{Antecedentes}

Los mapas conceptuales tienen sus antecedentes en la teoría de asimilación de David Ausubel. Esta hipótesis es el punto central sobre el aprendizaje significativo de tal manera que la mayor parte de este aprendizaje consiste en la asimilación de la nueva informacion (Ontoria, 2000).

En este sentido Ausubel (1989) defiende la idea de que la adquisición de información nueva depende en alto grado de la ideas pertinentes que ya existen en la estructura cognitiva y el aprendizaje significativo de los seres humanos ocurre a través de la interacción de de esa nueva informacion con las ideas pertinentes que ya existen en la estructura cognitiva.

El concepto de aprendizaje significativo fue concebido con la intención de superar los límites de la enseñanza tradicional. Este aprendizaje se presenta cuando "nuevos conocimientos pasan a significar algo para el estudiante, siendo capaz de integrar y explicitar dicho conocimiento, es decir, si explica algunas situaciones con sus propias palabras y emplea este conocimiento para la resolución e interpretación de nuevos problemas de distinto contextos (Díaz, 2002).

La adquisición del lenguaje es lo que permite en gran parte a los humanos el lenguaje significativo. Parece apropiado referirse a él como "el código que permite interpretar y /o relacionar lo captado. La palabra es un tipo especial de lenguaje que por su capacidad simbolizadora permite que el cerebro procese en forma integral la información que envía a cada uno de los sentidos, clasificando, ordenando y relacionando las imágenes o sensaciones percibidas. Es por ello que están estrechamente relacionados el significado, la interacción y el conocimiento de los objetos, expresados a través del lenguaje (Bedoya, 2004).

"Los mapas conceptuales no son la única forma de representación de conceptos, entre otras están los diagramas de flujo, los organigramas, las redes semánticas, los diagramas de precabilidad, pero ninguno de estos tipos de representaciones se basa en la teoría de del aprendizaje significativo ni en la teoría del conocimiento que constituyen la base de la elaboración de los mapas conceptuales (Bedoya, 2004, p.3).

\section{Definiciones conceptuales}

Dentro del proceso de investigación se han presentado en los últimos años, diferentes definiciones de mapas conceptuales, una de ellas es la presentada por Novak (1988) como una técnica que representa, simultáneamente, una estrategia de aprendizaje, un método para captar lo más significativo de un tema y un recurso esquemático para representar un conjunto de significados conceptuales, incluidos en una estructura de proposiciones.

"Mapa conceptual es una técnica usada para la representación gráfica del conocimiento. Un mapa conceptual es una red de conceptos. En la red, los nodos representan los conceptos, y los enlaces las relaciones entre los conceptos en forma de flechas etiquetadas (mapas conceptuales, 2005, p.2)

Desde este punto de vista considero que los mapas conceptuales son representaciones esquemáticas conceptuales que se estructuran con preposiciones donde las relaciones entre los conceptos tiene un alto grado de significación. 


\section{Características}

Los mapas conceptuales (2008) poseen características básicas tales como:

- Jerarquización: los conceptos más generales e inclusivos deben ubicarse en la parte superior del mapa y los conceptos más específicos en la parte inferior.

- Selección: Son una síntesis o resumen que contienen lo más significativo de un tema. Se pueden elaborar submapas: que amplíen diferentes partes o subtemas del tema principal.

- Impacto visual: Un buen mapa conceptual es conciso y muestra las relaciones entre las ideas principales de un modo simple y vistoso, sobre la base de la notable capacidad humana para la representación visual.

- Para las palabras de enlace, pueden utilizarse verbos, preposiciones, conjunciones, u otro tipo de nexo conceptual, estas dan sentido al mapa hasta para personas que no conozcan con amplitud sobre un tema.

- Si la idea principal puede dividirse en dos o más conceptos iguales, estos conceptos deben situarse en un mismo nivel o altura.

Los mapas conceptuales son representaciones esquemáticas del conocimiento acerca de un tema específico. En este esquema todo el conocimiento esta organizado y representado en niveles de abstracción situando los conceptos más generales e inclusivos en la parte superior del mapa y los menos inclusivos en la parte inferior del mismo.

\section{Componentes}

Los mapas conceptuales (2008) contienen elementos como:

- Los conceptos: Pueden considerarse como aquellas palabras con las que se designa cierta imagen de un objeto o de un acontecimiento en nuestra mente.

- Las palabras de enlace: Son las palabras o frases que sirven para unir los conceptos y expresar el tipo de relación existente entre ellos. Por ejemplo, para, se conoce como, posee, expresa, está formado por, es. Las palabras de enlace se escriben en la línea que une a dos nodos.

- Las proposiciones: Constituyen dos o más conceptos unidos por palabras de enlace para formar la unidad semántica más simple que tiene valor real.

\section{Tipología}

Se pueden elaborar mapas conceptuales (2008) muy diferentes, según el propósito que tengan, como por ejemplo:

- Mapa Jerárquico: en el que a partir del concepto principal (situado en la parte superior) va descendiendo verticalmente según el orden de importancia.

- Mapa en araña: que sitúa el tema principal en el centro y dibuja los temas subordinados a su alrededor, como las patas de una araña, de manera radial.

- Mapa de Organigrama: que organiza la información de manera lineal o bidimensional, pero indicando el flujo recomendado para la lectura, la forma de seguir la información o las decisiones que hay que adoptar según se va avanzando en su lectura y comprensión. 


\section{Ð1010 Importancia de los mapas conceptuales para la organización ...}

\section{Principios de aplicación}

Los principios para la elaboración de los mapas conceptuales (2008) son:

- Definir qué es un concepto y qué es una proposición.

- Representar la relación de los conceptos, sobre la base de un modelo de lo general a lo específico, en el que las ideas más generales o inclusivas, ocupen el ápice o parte superior de la estructura y las más específicas la parte inferior.

- Relacionar los conceptos en forma coherente, a partir de un ordenamiento lógico mediante palabras de enlace. Estas permiten, junto con los conceptos, construir frases u oraciones con significado lógico y proposicional.

- Lograr la mayor interrelación posible, donde se logre un aprendizaje que permita reconocer y reconciliar los nuevos conceptos con los aprendidos y poder combinarlos.

\section{Usos}

Los mapas conceptuales (2008) pueden ser empleados como una técnica de estudio y como herramienta para el aprendizaje, ya que le permiten al docente explorar con sus alumnos los conocimientos previos que tienen frente a un tema específico. También sirven para:

Generar y organizar ideas:

- tomar apuntes, resumir y analizar un texto (para ordenar las ideas sin tener en cuenta el orden en el cual se transmiten);

- escritura creativa (escribir sus palabras clave y organizar las ideas en categorías principales y subcategorías hasta llegar al plan del texto)

- organizar el trabajo propio

Representar y organizar el conocimiento:

- representando un dominio de conocimiento concreto y sus interrelaciones

- $\quad$ señalando las interacciones entre los conceptos

- aprendiendo eficazmente

- facilitando la navegación

Comunicar y compartir:

- una información con una estructura temática compleja

- información en red de forma estructurada

Tomar decisiones:

- en el proceso de autoaprendizaje

- en trabajos en equipo

- en decisiones profesionales

La elaboración de mapas conceptuales le permite al alumno organizar, interrelacionar y fijar el conocimiento del contenido estudiado, fomentando la reflexión el análisis y la creatividad. 


\section{Capítulo 2 - La organización de contenidos en las Ciencias de la Información}

Desde épocas inmemorables, el hombre ha sentido necesidad de representar las cosas que le rodean. Tanto fue así, que las primeras formas de representación de la información que se conocen son las pinturas rupestres, a éstas sucedieron las tabletas de arcilla, el papiro, los pergaminos y otros.

Años más tarde, "con el surgimiento del papel y la imprenta, apareció el libro impreso como forma superior de organizar y representar la información existente hasta el momento y crear las bases de una cultura que perdura actualmente en las ciencias" (Castillo, 2006, p.4).

La Ciencias de la Información es una ciencia social que se aplica con una visión multidisciplinar que incluye dentro de su amplia gama de estudios la organización y representación de la información tanto en formato digital como impreso.

\section{Organización y representación de contenidos}

"La información es todo aquel conjunto organizado de datos que constituye un mensaje sobre determinada cosa, evento, fenómeno, donde su uso racional es la base del conocimiento” (Ponjuán, 2004, p.20).

La organización de información se ha relacionado directamente con la conocida etapa del procesamiento de la información y se ha enmarcado dentro de los aspectos tradicionales de la misma, que de forma genérica, "se pueden resumir como todo lo relacionado con la descripcion de forma y contenido de los documentos que entran a formar parte del sistema" (Vizcaya, 2004, p.35).

Este proceso lo utilizan los profesionales de la información para estructurar y difundir sistemas de información. Dichos procesos se realizan con vistas a lograr una mayor calidad en los servicios de información que brindar hacia los usuarios, y con ello la satisfacción de las necesidades de los mismos con la eficiencia en la recuperación de la información.

El análisis documental es una etapa muy importante en el proceso de organización y representación de la información. "El análisis adecuado de un documento requiere la selección de las ideas informativamente relevantes del mismo a fin de expresar su contenido sin ambigüedades para recuperar la información en él contenida". (Hernández, 2004, p.32).

"La representación puede ser utilizada para identificar el documento, para procurar los puntos de acceso en la búsqueda de documentos, para indicar su contenido o para servir de sustituto del documento. El análisis puede tomar la forma de un sumario, un resumen, un índice alfabético de materias o códigos sistemáticos” (Godoy, 2007, p.1)

Los puntos de acceso se realizan mediante la catalogación como el proceso que pretende establecer la lista de documentos que componen una colección, es decir, el catálogo, considerado éste como instrumento de comunicación entre la colección y los usuarios. En este sentido se ocupa de diseñar las formas de acceso o puntos de entrada que los documentos tengan en el catálogo con el objeto de que puedan ser recuperados; esto en la práctica implica también operaciones propias del análisis de contenido.

La clasificación es otro medio que funciona como un conjunto ordenado de conceptos que se presentan distribuidos sistemáticamente en clases conformando una estructura. La misma representa el documento y la rama del conocimiento a la que pertenece esta materia o sea la clasificación permite ordenar el conocimiento función importantísima para la recuperación de la información. Las clasificaciones más extendidas en el mundo son: CDU (Clasificación Decimal Universal), la Clasificación Decimal Dewey y la LCC (Clasificación de la Biblioteca del Congreso de Washington).

La indización no deja de ser importante ya que técnica del análisis documental para representar y describir el contenido de los documentos, mediante conceptos principales contenidos en ellos (palabras clave) o vocabularios controlados (descriptores, términos o encabezamientos de materia), con el fin de guiar al usuario en la recuperación de los documentos que necesita la indizacion en la documentación. Este proceso esencial produce grandes aportes en la organización y representacion de la información lo cual posee cualidades como son: 
Importancia de los mapas conceptuales para la organización ...

- Pertinencia: Ajustar con mayor efectividad posible el empleo de un término útil para el usuario y útil en la representación del documento.

- Exhaustividad: Ofrecer el mayor repertorio posible y pertinente de temas, conceptos y objetos representados en el documento. En función del tipo de unidad informativa, puede ser útil una baja exhaustividad, (hasta 8 términos), una media exhaustividad (entre 8 y 12) o una alta (más de 12)

- Especificidad: Grado de precisión de los términos seleccionados en una recuperación. Está en relación directa con la eliminación de ambigüedades del lenguaje natural (sinonimias, polisemias) También se halla en relación directa con la correcta jerarquización de los términos así como con una controlada asociación de términos equivalentes.

- Uniformidad: Grado de coincidencia en el uso de los términos por parte de un usuario recuperando información y un documentalista indizando. Se mide por la coherencia del lenguaje documental (Pinto, 2008, p.1).

Tipos de indización:

- Libre: Aquella en la que la identificación se realiza a través de una lista o conjunto abierto de términos.

- Controlada: Aquella en la que la identificación se realiza por medio de una lista o conjunto cerrado de términos (Hernández, 2004, p. 360).

La catalogación, la clasificación e indización son métodos tradicionales de organización y representación de la información que han sido aplicados a lo largo de la historia en las instituciones de información.

\section{Organización y representación de contenidos en la Web}

"Con el surgimiento de las nuevas tecnologías de la información y las comunicaciones se hace necesario en un entorno electrónico saber organizar los contenidos electrónicos, analizarlos, procesarlos, filtrarlos y representarlos de forma sintética" (Pinto, 2008, p.1).

Zea (2004) plantea que las herramientas que se crean y se utilizan para organizar los documentos científicos generados por estas nuevas temáticas en los sistemas de información siguen teniendo o están influidas de alguna manera por una visión disciplinar de las ciencias sociales.

La organización y representación de información en la web es uno de los roles que ha asumido el profesional de la información. Con la arquitectura de la información se crean las bases para facilitar al máximo los procesos de comprensión y asimilación de la información, así como las tareas que ejecutan los usuarios en un espacio de información definido.

"La Arquitectura de la Información trata indistintamente del diseño de sitios web, interfaces de dispositivos móviles (como los lectores de mp3), CDs interactivos, videoclips digitales, relojes, tableros de instrumentos de aviones de combate o civiles, interfaces de máquinas dispensadoras, interfaces de juegos electrónicos " (Ronda,2005,p.45).

"El conocimiento es aquel conjunto de saberes, que se dan a diferentes niveles, que poseemos sobre algo" (Ponjuan, 2006, p.55). La organización y representación del conocimiento es una nueva tendencia que están adquiriendo los sistemas de información para ganar e competitividad. Este modelo va más allá de la organización de la información ya que trata de optimizar la organización de los repertorios de conocimiento existentes en un dominio, para facilitar la recuperación, creación y compartición de conocimiento entre la comunidad de usuarios.

Ponjuán (2006) resalta que existen formas documentales de organización y representación del conocimiento consolidadas en el funcionamiento de los sistemas de información, como son por ejemplo:

- Los mapas conceptuales Es un documento o conjunto de documentos SGML y XML, interrelacionados en un espacio multidimensional en el que las localizaciones son temas. Son herramientas empleadas para la gestión del conocimiento y la optimización de la recuperación de información. 
- Las ontologías que ofrecen el conocimiento de un dominio de forma compartida y consensuada, ya sea entre personas, sistemas heterogéneos. Se definen como una especificación formal (legible por máquina), explicita de una conceptualización compartida, en la que los conceptos están organizados en forma de taxonomía.

- Un tesauro es una herramienta documental utilizada en el ámbito de la representación y recuperación de información, que representa un ámbito del conocimiento determinado mediante su estructuración conceptual.

Se ha constatado que el empleo de las formas documentales anteriormente descritas facilitan la economía cognitiva de gestores y usuarios al conseguir representar el máximo de información sobre un objeto usando el mínimo de recursos conceptuales (Pinto, 2008).

Ahora bien, estas formas documentales pueden ser filtradas mediante los resúmenes como breves textos representativos, autónomos, intencionales, de gran textualidad, coherencia y cohesión; su autonomía, o independencia documental con respecto al texto de partida y su diversidad.

Para la elaboración de resúmenes de los documentos el profesional de la información no debe perder de vista el análisis del discurso. Este último se basa en los modelos mentales que se tienen de un acontecimiento y, por motivos como: el conocimiento del receptor, las especificidades de los canales de comunicación y de los recursos de información, sólo expresa una parte de la información y se deja implícita otra parte de ella en la enunciación (Hernández, 2004).

La Ciencia de la Información y los profesionales que laboran en la disciplina han desarrollado sistemas muy eficientes que permiten organizar y representar la información y el conocimiento de los procesos meta cognitivos del individuo. Esto ha impulsado las investigaciones de autores desde diferentes disciplinas en el ámbito social.

\section{Capítulo 3 - Influencia de los mapas conceptuales en la organización y representación de los contenidos en las Ciencias de la Información}

Los mapas conceptuales pueden tener estructuras y representar relaciones mucho más complejas y extensas que las que permite el lenguaje verbal. Pueden ser muy útiles en el procesamiento de la información con la idea de mostrar la mera existencia de interrelaciones entre diversos temas y, eventualmente, su agrupación u orden.

\section{Mapas conceptuales en el procesamiento de la información}

En las Ciencias de la Información el análisis del discurso es un paso previo al procesamiento de información. El análisis tiene significados globales (los temas), que representan la información más importante y explican de qué se trata en general el texto". Los temas son la información de un discurso que mejor se interpretan, recuerdan o reconocen, aunque son reflejo del significado de todo el texto 0 , al menos de un fragmento de este, y pueden representarse en el propio texto, en especial si es escrito, en forma de resumen, título o subtítulo (Zaldua,2006).

Desde este punto de vista el profesional de la información puede analizar el contenido de un discurso y representar gráficamente la interrelación de los temas tratados en una revista, desde su creación, a partir de la coocurrencia de palabras significativas en las distintas oraciones.

"Los diagramas de flujo, un tipo de mapa conceptual utilizado en la programación de actividades" (Zaldua, 2006, p.2). Este diseño resulta de gran utilidad en la visualización del flujo de información presente en los sistemas de información, lo cual le permite al profesional de la información tener una visión más amplia del estado y hacia donde están encaminados los objetivos de la institución en las secuencias de acciones.

Si bien los sistemas de clasificación pueden ser representados mediante diagramas de conjuntos, el análisis de una significación que recurra a relaciones jerárquicas, como ocurre habitualmente en la memoria, puede exigir otro tipo de gráfico como los mapas conceptuales situando los conceptos más generales e inclusivos en la parte superior del mapa y los más específicos, progresivamente, hacia abajo y hacia la derecha.

Los mapas conceptuales pueden ser una excelente manera de elaboración de resúmenes y de aprender una materia. Esta interrelación conceptual ofrece una manera visual de aprendizaje donde se concentra en un mismo 
plano toda la información más importante de un documento. Con la realización de este tipo de gráfico se pueden diseñar mapas subordinados unos a otros, lo que permite la construcción y consulta de mapas muy complejos, especialmente útiles para guiar a los usuarios de sitios web.

Sandoval (2006) refleja que el análisis bibliográfico de una obra requiere de una serie de pasos estratégicos en la representación de sus puntos de acceso para su recuperación Para la utilización de los mapas conceptuales en el proceso de catalogación se puede seguir el siguiente orden:

Primero se revisan los títulos y subtítulos de los capítulos y apartados. Se extraen y enlistan los conceptos más relevantes (que pueden coincidir con los más citados). Se les asigna un orden jerárquico a cada uno de ellos; se colocan en un mapa de tres o más niveles; el primero será para el más general, los intermedios serán para los particulares y los inferiores para las facetas o los términos menos inclusivos. Estos conceptos se incluyen dentro de óvalos y se conectan a través de flechas que indiquen el orden y la dirección de las posibles proposiciones que se habrán de establecer; en las flechas se incluyen términos que enlacen de manera lógica cada uno de los conceptos.

Una vez establecidas las proposiciones, se analiza cual de ellas resulta más extensiva. Esto incluye a las demás, ya que a ésta puede ser el tema principal y al cual habrá que hacer coincidir con nuestros términos controlados. Si las otras se consideran relevantes para formarse una idea completa de la obra, se pueden utilizar como encabezamientos de materia secundarios.

\section{Mapas conceptuales en la arquitectura de la información}

La hipertextualidad es una característica de la nueva visión del texto en formato digital. La arquitectura de información es una rama de la ciencia de la información que estudia y crea sistemas hipertextuales, entendiendo al hipertexto como textos o programas en formato digital que poseen enlaces hipertextuales con una interfaz no lineal y discontinua.

El diseño previo de un mapa conceptual debe ser una herramienta imprescindible para la elaboración de un hipertexto, pero también los mapas conceptuales deben ser componentes básicos de cualquier sistema de hipertexto, complementando texto e imágenes con diagramas formales y semiformales activos que pueden ser presentados en pantalla para facilitar la lectura hipertextual (Laverde, 2005). De igual modo el mismo autor expone las herramientas de navegación como vías diseñadas para la accesibilidad de los hipertextos. Por ello, el uso de mapas conceptuales en los sistemas de hipertexto permite 4 objetivos fundamentales:

- Diseñar el hipertexto

- Facilitar la navegación

- Representar el conocimiento

- Evaluar dicho conocimiento

Estos objetivos se observan más directamente a través de las aplicaciones de los mapas conceptuales que se muestran a continuación.

\section{Mapas conceptuales como sistemas de navegación Web}

Los mapas conceptuales son un magnífico medio para navegar en la web. Internet ha resultado en una enorme cantidad de información disponible para todos aquellos que tengan acceso a la red. Este fácil acceso a documentos y conocimiento, en todas las áreas del saber y en todos los medios, ha impulsado la introducción de la tecnología en escuelas de todo el mundo con el objetivo de que esté al alcance de los estudiantes e inspira a ciudadanos de todos los países a pasar horas navegando por la red, buscando información.

"Uno de los ejemplos es un mapa conceptual acerca de la capa de ozono, desarrollado por el Instituto de Cognición Humana en Estados Unidos. El mapa es un resumen de las principales características del ozono. Cada uno de los íconos que compone el mapa representa informacion adicional sobre el correspondiente concepto. Esta información puede estar en forma de imágenes, videos, sonido, paginas Web, y otros mapas conceptuales" (Laverde, 2005, p.3).

Los enlaces entre los mapas se establecen por relación de contenidos, no por secuencia Cualquier mapa sirve como punto de partida y de acuerdo con el interés o la necesidad la persona que está investigando o buscando la 
información puede navegar a otros mapas relacionados. El problema de la navegación, perdidos en el hiperespacio, común en los sistemas de multimedia y persistente en la navegación de la web, se resuelve fácilmente en la navegación con mapas conceptuales.

"El principal problema de la web es que los enlaces entre las páginas no tienen semántica para relacionar el origen y el destino. En la mayoría de los casos, la informacion en la pagina destino es de diferente contexto que la de la pagina de origen" (Lamarca, 2006). En la navegación de mapas conceptuales todas las ligas tienen semántica, ya sea explicita en el mapa o por contexto al navegar entre mapas $u$ otros medios. El usuario sabe siempre hacia donde va al seguir una liga, en contraste con otras herramientas de navegación.

\section{Mapas conceptuales en la organización de contenidos}

La organización de contenidos en la Web a pesar de que sufre de problemas de navegación, se apoya en la poderosa herramienta que permite estructurar el contenido.

Los mapas conceptuales proveen una interfaz elegante y fácil de comprender para navegar en un sistema de multimedia. Relaciones de generalización y especialización entre otros conceptos conllevan a una organización jerárquica de mapas conceptuales.

En el Instituto de Cognición Humana en Estados Unidos se han desarrollado un conjunto de herramientas computacionales que permite utilizar mapas conceptuales para organizar contenidos. El software permite disponer grandes cantidades de documentación como imágenes, videos, paginas Web de tal forma que el acceso sea flexible y fácil, navegando a través de mapas conceptuales (Cañas, 1997).

El Cmap Tools es la herramienta computacional usada para diseñar el mapa conceptual Esta permite al usuario construir mapas conceptuales como herramientas de navegación. La arquitectura distribuida del sistema permite que los diversos medios y mapas se almacenen en diferentes servidores en una red y que puedan acceder desde cualquier nodo en la red. Aprovechando la extensión de Internet se puede entonces construir sistemas de multimedia accesibles desde cualquier lugar del mundo (Cañas, 1997).

Los mapas conceptuales permiten representar a través de los contenidos un modelo de conocimiento de un experto reconocido en el área. "Este incluye las particularidades de la forma en que el experto lleva a cabo el diagnóstico, las cuales usualmente no se encuentran en un manual y precisamente lo caracterizan como experto (Cañas, 1997).

Los mapas conceptuales, junto con los componentes de diagnóstico y apoyo en el trabajo y su funcionamiento a través de la red, proveen el apoyo necesario en casos en los cuales el técnico necesita capacitación en el justo momento en que requiere arreglar él o requiere de un curso de repaso. Al mismo tiempo, el sistema también pretende aumentar comprensión conceptual del técnico sobre el funcionamiento del equipo.

\section{Conclusiones}

Para elaborar mapas conceptuales se requiere dominar los conocimientos que las personas poseen. Lo más importante en este proceso son las relaciones que se establezcan entre los conceptos a través de las palabrasenlace que permitan configuran la realidad del tema estudiado. La Ciencia de la Información ha encontrado en la utilización de los mapas conceptuales un recurso muy práctico y flexible que le permite crear, estructurar y ofrecer información. Las organizaciones de información cuentan con profesionales de información que dominan la información y el conocimiento, lo cual resultan muy manipulable la aplicación de los mapas conceptuales como recursos, no rígidos, que se ajustan muy bien a las necesidades cambiantes de los usuarios. 
Bílí. Importancia de los mapas conceptuales para la organización ...

\section{Bibliografía}

Hernández Quintana, A. (2004). Indización y resumen. La Habana: Editorial Félix Varela.

Ponjuán Dante, Gloria. (2006). Introducción a la gestión del conocimiento. La Habana: Editorial Félix Varela.

Ponjuán Dante, Gloria. (2004). Gestión de Información. Principios, conceptos y aplicaciones. Editorial Félix Varela: La Habana, Cuba.

Ronda León, R. (2005). Productos electrónicos .Principios y pautas . La Habana: Editorial Félix Varela.

Vizcaya, D. (2004). Fundamentos de la Organización de la información. La Habana: Editorial Félix Varela.

Zaldua, A. (2006). El análisis del discurso en la organización y representación de la información-conocimiento: elementos teóricos .Acimed.14 (3). Cuba.

Zea Restrepo, C. (2004). Entendiendo las Ciencias con mapas conceptuales. Revista Universidad EAFIT. Abril 2004,34 (10-24). Colombia

\section{Referencias bibliográficas complementarias}

1- Linares, R. (2005). Ciencia de la Información: Historia y epistemología. Bogotá: Rojas Eberhard (on-line). Disponible en: http://bvs.sld.cu/revistas/aci/vol14 4 06/aci18406.htm

2- Ontoria (2000). Citado en Bedoya Beltrán, J. (2004). Los mapas conceptuales como herramientas de evaluación del lenguaje en las ciencias básicas. Universidad de Antioquia (on-line). Disponible en: http://faccbi.ucpr.edu.co/encuentrosdcb/historial/PrimerEncuentro/PONENCIAS\%20PRIMER\%20ENCUENTRO/Mapas conceptuale s como herramienta de evalaucion Jorge Alberto Bedoya I.pdf

3- Ausubel (1989). Citado en Bedoya Beltrán, J (2004). Los mapas conceptuales como herramientas de evaluación del lenguaje en las ciencias básicas. Universidad de Antioquia (on-line). Disponible en:

http://faccbi.ucpr.edu.co/encuentrosdcb/historial/PrimerEncuentro/PONENCIAS\%20PRIMER\%20ENCUENTRO/Mapas conceptuale $\underline{\text { s como herramienta de evalaucion Jorge Alberto Bedoya I.pdf }}$

4- Díaz (2002). Citado en Bedoya Beltrán, J. (2004). Los mapas conceptuales como herramientas de evaluación del lenguaje en las ciencias básicas. Universidad de Antioquia (on-line). Disponible en:

http://faccbi.ucpr.edu.co/encuentrosdcb/historial/PrimerEncuentro/PONENCIAS\%20PRIMER\%20ENCUENTRO/Mapas conceptuale $\underline{\text { s como herramienta de evalaucion Jorge Alberto Bedoya I.pdf }}$

5- Bedoya Beltrán, J. (2004). Los mapas conceptuales como herramientas de evaluación del lenguaje en las ciencias básicas. Universidad de Antioquia (on-line). Disponible en: http://faccbi.ucpr.edu.co/encuentrosdcb/historial/PrimerEncuentro/PONENCIAS\%20PRIMER\%20ENCUENTRO/Mapas conceptuale s como herramienta de evalaucion Jorge Alberto Bedoya I.pdf

6- Novak (1988). Citado en Cuevas, A. (2005). Propuesta de aplicación de los mapas conceptuales en un modelo pedagógico semipresencial (on-line). Disponible en: http://www.rieoei.org/deloslectores/493Cuevas.PDF

7- Definiciones y tipos de mapas conceptuales. (2005). (on-line). Disponible en:

http://auxidurancoton.blogspot.com.br/2007/11/definicin-y-tipos-de-mapas-conceptuales.html

8- Los mapas conceptuales para ordenar, motivar y procesar. (2008). Disponible en:

http://www.luisocampo.pro.bo/descargas/mapas conceptuales.PDF

9- Castillo Zayas, Mariela del (2006). Organización y representación de la información: el formato impreso y el hipertexto.

Acimed,14(4).(on-line). Disponible en: http://bvs.sld.cu/revistas/aci/vol14 4 06/aci14406.htm

10- Ponjuán Dante, G (2004).Gestión de Información. Principios, conceptos y aplicaciones. La Habana: Editorial Félix Varela.

11- Vizcaya, D (2004).Fundamentos de la Organización de la información. La Habana: Editorial Félix Varela.

12- Hernández Quintana, A. (2004). Indización y resumen. La Habana: Editorial Félix Varela. 
$51010 \mathrm{C} 0 \mathrm{Importance}$ of concept maps for the organization...

13- Godoy, M (2007). Qué es la información?.Curso Básico de procesamiento de información homologados por el Gobierno de Canarias (on-line) .Disponible en: http://www.misrespuestas.com/que-es-la-informacion.html

14- Pinto Molina, M. (2008).Organización, representación y filtración de la informacion (on-line). Disponible en: http://www.mariapinto.es/e-coms/or con elect.htm

15- Zea Restrepo, C. (2004). Entendiendo las Ciencias con mapas conceptuales. Revista Universidad EAFIT. Abril ,34 (10-24).

16- Ronda León, R. (2005). Productos electrónicos. Principios y pautas. La Habana: Editorial Félix Varela.

17- Ponjuán Dante, G. (2006). Introducción a la gestión del conocimiento. La Habana: Editorial Félix Varela.

18- Zaldua, A. (2006). El análisis del discurso en la organización y representación de la información-conocimiento: elementos teóricos .Acimed.14 (3).

19- Sandoval Álvarez, J. (2006). Los mapas conceptuales y la catalogación temática. Universidad Autónoma de México (on-line). Disponible en: http//www.catalogacion tematicaunam.htm

20- Laverde, A. (2005). Citado en Ronda León, R (2008). Arquitectura de Información: análisis histórico-conceptual. No Solo Usabilidad journal, ํㅜ 7. (on-line). Disponible en: http://www.nosolousabilidad.com/articulos/historia arquitectura informacion.htm.

21- Lamarca Lapuente, M. (2006). Hipertexto: El nuevo concepto de documento en la cultura de la imagen (on-line). Disponible en: http://www.hipertexto.info/

22- Cañas (1997) Citado en Ronda León, R (2005).Productos electrónicos .Principios y pautas. La Habana: Editorial Félix Varela.

\section{Datos de la autora}

Suleidy Contreras Rodriguez

Licenciada en Bibliotecologia y Ciencias de la Información en la Facultad de Comunicación de la Universidad de la Habana. Me desempeño como Especialista en archivística en el departamento de Servicios de Información y Automatización del Centro.

suleidyc@ahp.vcl.cu

Recibido - Received: 2011-08-09

Aceptado - Accepted: 2011-09-30 